\title{
Propofol detection for monitoring of intravenous anaesthesia: a review
}

\author{
David C. Ferrier $^{1}$ [D $\cdot$ Janice Kiely ${ }^{1} \cdot$ Richard Luxton $^{1}$
}

Received: 4 September 2020 / Accepted: 28 June 2021 / Published online: 2 July 2021

(c) The Author(s) 2021

\begin{abstract}
This paper presents a review of established and emerging methods for detecting and quantifying the intravenous anaesthetic propofol in solution. There is growing evidence of numerous advantages of total intravenous anaesthesia using propofol compared to conventional volatile-based anaesthesia, both in terms of patient outcomes and environmental impact. However, volatile-based anaesthesia still accounts for the vast majority of administered general anaesthetics, largely due to a lack of techniques for real-time monitoring of patient blood propofol concentration. Herein, propofol detection techniques that have been developed to date are reviewed alongside a discussion of remaining challenges.
\end{abstract}

Keywords Propofol ·2,6-Diisopropylphenol $\cdot$ Real-time monitoring $\cdot$ Optical detection $\cdot$ Electrochemical detection

\section{Introduction}

Propofol (2,6-diisopropylphenol) is an intravenous drug used for the induction and maintenance of anaesthesia. It has favourable characteristics, including rapid induction and a short half-life, and consequently it has been the most commonly used intravenous anaesthetic for the last 30 years [1, 2].

Until recently, the most common practice in general anaesthesia was to use an intravenous anaesthetic, such as propofol, for the induction phase and volatile anaesthetics for the maintenance phase [3]. However, it is possible to use propofol for both the induction and maintenance phases, in a process known as total intravenous anaesthesia (TIVA). There is a growing body of evidence of the advantages of TIVA over the more conventional volatile-based anaesthesia, including: reduced short-term side-effects [3], reduced cognitive effects [4-6], the potential for improved long-term survival rates for cancer patients $[7,8]$, and a significantly reduced environmental impact [9-11].

Despite these numerous advantages, conventional volatile-based anaesthesia still accounts for the vast majority of administered general anaesthetics world-wide [3]. One

David C. Ferrier

David.Ferrier@uwe.ac.uk

1 Institute of Bio-Sensing Technology, University of the West of England, Frenchay Campus, Bristol BS16 1QY, UK significant obstacle to a greater exploitation of TIVA is the lack of suitable methods for the continuous, real-time monitoring of blood propofol concentration in patients undergoing anaesthesia.

This paper presents a review of solution-phase propofol detection techniques and their potential application to realtime propofol monitoring. To the authors' knowledge this represents the first review of propofol detection. There are also researchers who have investigated monitoring propofol in exhaled breath [3, 12-14]. However, as the relationship between blood propofol concentration and exhaled breath concentration is not fully understood [15], it remains unclear whether this approach will be applicable to patient monitoring; and gaseous propofol detection techniques will not therefore be covered in this review.

\section{Detection methods}

\subsection{Chromatography}

High performance liquid chromatography (HPLC) is perhaps the most commonly reported method for the detection and quantification of propofol, and considered by many to be the 'gold standard' for validation purposes. HPLC may be used in conjunction with a variety of measurement techniques, with the most common being fluorometric detection. 
When using fluorometric detection, the most common excitation and emission wavelengths are $276 \mathrm{~nm}$ and $310 \mathrm{~nm}$ respectively [16-19], however, the use of other wavelengths has been reported [20]. Typically, the mobile phases consist of mixtures of either methanol [16] or acetonitrile [17, 18] with water. Nishio et al. have demonstrated propofol detection using fluorometric-HPLC using only water as a mobile phase by utilising a temperature-responsive polymer as a stationary phase [19]. Fluorometric-HPLC has been demonstrated for the detection of propofol from serum and whole blood samples, with the samples being pre-treated either by precipitation of proteins using acetonitrile [16-18] or by solid phase extraction [19]. Reported limits of quantification range between 3 and $400 \mathrm{ng} / \mathrm{ml}[17,18]$, with linear ranges typically extending up to the order of $10 \mu \mathrm{g} / \mathrm{ml}$.

Another common measurement technique used in conjunction with HPLC is UV photometry. Absorbance is measured at wavelengths ranging from 210 to $280 \mathrm{~nm}$ [21, 22 ] and the mobile phases typically consist of acetonitrile mixed with either an acidic buffer [21,23] or ammonium [22]. Reported linear regions range from the order of 10 to $100 \mu \mathrm{g} / \mathrm{ml}$ and limits of quantification as low as $20 \mathrm{ng} / \mathrm{ml}$ have been reported [23].

The use of electrochemical measurement in conjunction with HPLC has also been reported, although this approach appears less common. Dowrie et al. have reported electrochemical detection of propofol from human serum and plasma using a mixture of methanol and an acidic buffer for the mobile phase and a measurement potential of $+0.8 \mathrm{~V}$ [24]. This group reports a linear range of 0.01 to $1 \mu \mathrm{g} / \mathrm{ml}$. Pissinis et al. have utilised a highly alkaline mobile phase as at a higher $\mathrm{pH}$ propofol will be ionised and therefore oxidation can be carried out at a lower potential $(\mathrm{ca} .+0.1 \mathrm{~V})$, resulting in reduced interference [25]. Using this method, they report a limit of detection of $5 \mathrm{ng} / \mathrm{ml}$. A summary of HPLC-based propofol detection techniques is presented in Table 1.

Whilst it may be a ubiquitous technique, HPLC is not well suited to point-of-care applications due to its reliance on bulky and expensive equipment. Furthermore, HPLC offers only discrete, rather than continuous measurement. It also requires complex and time-consuming sample pretreatment methods.

Mass spectrometry is another common technique for the detection and quantification of propofol in biological samples, in conjunction with either gas chromatography [26-28] or liquid chromatography [29-32]. As for HPLC, when analysing propofol in whole blood, serum or plasma, the propofol is extracted from the sample either by solvent $[26,27]$ or solid phase extraction [29, 31].

Gas chromatography-mass spectrometry (GC-MS) has been demonstrated to be capable of detecting propofol in blood samples with lower limits between 2.5 and $10 \mathrm{ng} /$ $\mathrm{ml}[26,27]$, with linear ranges between 0.01 and $10 \mu \mathrm{g} / \mathrm{ml}$. Similar values have been reported for liquid chromatography tandem mass spectrometry (LC-MS/MS) [29, 31, 32] although Vaiano et al. have reported a detection limit of $0.1 \mathrm{ng} / \mathrm{ml}$ from whole blood using this technique [33]. A summary of mass spectrometry-based propofol detection techniques is presented in Table 2.

As for HPLC, the principle disadvantages of mass spectrometry techniques are the requirement for expensive and bulky equipment and the lack of capacity for continuous monitoring. A particular drawback is the requirement for lengthy analysis and sample preparation processes, with one group reporting analysis times of $40 \mathrm{~min}$ and sample preparation times of $300 \mathrm{~min}$ [28].

Table 1 Summary of reported HPLC propofol detection and quantification techniques

\begin{tabular}{|c|c|c|c|c|c|}
\hline Measurement & Mobile phase & Extraction & $\mathrm{LoQ}^{\mathrm{a}}(\mathrm{ng} / \mathrm{ml})$ & Range $(\mu \mathrm{g} / \mathrm{ml})$ & References \\
\hline Fluorescent & Methanol/water & Acetonitrile & 50 & $1-10$ & {$[16]$} \\
\hline Fluorescent & Acetonitrile/water/trifluoroacetic acid & Acetonitrile & 400 & $0.4-40$ & [17] \\
\hline Fluorescent & Acetonitrile/water & Acetonitrile & 3 & $0.05-10$ & {$[18]$} \\
\hline Fluorescent & Water & Solid-phase & NR & $0.5-10$ & [19] \\
\hline Fluorescent & Methanol/phosphate buffer ( $\mathrm{pH} 4.5$ ) & Methanol & 100 & $0.1-3$ & {$[20]$} \\
\hline UV & Acetonitrile/buffer ( $\mathrm{pH} 2.5$ ) & $\mathrm{NR}$ & 750 & $15-75$ & {$[21]$} \\
\hline UV & Acetonitrile/ammonium & NR & NR & $37-592$ & {$[22]$} \\
\hline UV & Acetonitrile/buffer ( $\mathrm{pH} 3$ ) & Solid-phase & 20 & NR & {$[23]$} \\
\hline Electrochemical & Methanol/phosphate buffer (pH 2.8) & Pentane & 5 & $0.01-1$ & {$[24]$} \\
\hline Electrochemical & Acetonitrile/buffer & NR & 15 & NR & [25] \\
\hline
\end{tabular}

$N R$ not reported

${ }^{a}$ Where a limit of detection $(\mathrm{LoD})$ is stated in preference to a limit of quantification (LoQ), LoQ is assumed to be three times LoD 
Table 2 Summary of reported mass spectrometry propofol detection and quantification techniques

\begin{tabular}{lllll}
\hline Technique & Extraction & LoQ $^{\mathrm{a}}(\mathrm{ng} / \mathrm{ml})$ & Range $(\mu \mathrm{g} / \mathrm{ml})$ & References \\
\hline GC-MS & Chloroform-ethyl acetate & 10 & $0.01-10$ & {$[26]$} \\
GC-MS & Heptane & 7.5 & $0.01-5$ & {$[27]$} \\
GC-MS & Ethyl acetate & 325 & $\mathrm{NR}$ & {$[28]$} \\
GC-MS & Dichloromethane/ethyl acetate & 5 & $\mathrm{NR}$ & {$[33]$} \\
LC-MS/MS & Solid-phase & 5 & $0.005-2$ & {$[29]$} \\
LC-MS/MS & Acetone & $\mathrm{NR}$ & $0.02-20$ & {$[30]$} \\
LC-MS/MS & Solid-phase & $\mathrm{NR}$ & $0.01-1.5$ & {$[31]$} \\
LC-MS/MS & Methanol-acetonitrile/solid-phase & 10 & $0.01-10$ & {$[32]$} \\
LC-MS/MS & Dichloromethane/ethyl acetate & 0.1 & $\mathrm{NR}$ & {$[33]$} \\
\hline
\end{tabular}

${ }^{\mathrm{a}}$ Where a limit of detection (LoD) is stated in preference to a limit of quantification (LoQ), LoQ is assumed to be three times LoD

$N R$ not reported

\subsection{Optical techniques}

To achieve the spectrophotometric detection of propofol, many groups have taken advantage of the Gibbs reaction. This is the name given to the process wherein 2,6-dichloroquinone-4-chlorimide (DCQ), also known as Gibbs' reagent, reacts with phenolic compounds in alkaline conditions to produce an indophenol (Fig. 1) [34, 35]. This indophenol will be a blue-to-violet coloured species with an absorption maximum of approximately $600 \mathrm{~nm}$.

Gad-Kariem and Abounassif have exploited this reaction to demonstrate the detection of propofol in biological fluids by mixing samples with DCQ solution, dimethyl sulfoxide and a buffer ( $\mathrm{pH} 9.6$ ), allowing the mixture to react for $15 \mathrm{~min}$ and then measuring the absorbance at $635 \mathrm{~nm}$ [36]. By this method this group were able to demonstrate the detection of propofol in spiked plasma and urine with a linear range of $1-5 \mu \mathrm{g} / \mathrm{ml}$ and a detection limit in plasma of $0.28 \mu \mathrm{g} / \mathrm{ml}$.

Hong et al. have also made use of the Gibbs reaction [37]. This group have developed a disposable microfluidic chip containing a molecularly imprinted polymer (MIP) for the solid phase extraction of propofol. The MIP film is synthesised by the UV-initiated co-polymerisation of methacrylic acid and ethylene glycol dimethacrylate. The chip is used in conjunction with a laser diode and photodetector to measure the absorbance of the MIP at $655 \mathrm{~nm}$, after mixing the analyte solution with DCQ within the microfluidic device. In this manner this group has demonstrated the detection of propofol in methanol solution across the range 0.25 to $10 \mu \mathrm{g} /$ $\mathrm{ml}$. It is reported that this set-up returns the propofol concentration within $60 \mathrm{~s}$. However, the device cannot accommodate whole blood and this timeframe does not include the sample preparation time that would be required if working with blood, serum or plasma.

Liu et al. have also demonstrated the spectrophotometric detection of propofol by exploiting the Gibbs reaction [38]. This group have used the Pelorus 1000 system (Sphere Medical Ltd.). In this system a $0.7 \mathrm{ml}$ sample of whole blood is diluted and the red blood cells lysed. Propofol is then extracted from the lysed blood by solid phase extraction and reacted with DCQ. The resultant indophenol is then detected via colourimetry. Using this system, the authors reported a limit of quantification for propofol in whole blood of $0.75 \mu \mathrm{g} / \mathrm{ml}$ with a linear response up to $12 \mu \mathrm{g} / \mathrm{ml}$. It is reported that the time-to-results is approximately $5 \mathrm{~min}$ and that no sample preparation, beyond that performed automatically by the system, is required. This same system has been used to measure the blood propofol concentration of ponies under anaesthesia [39].

Sramkova et al. have demonstrated an alternative approach for the spectrophotometric detection of propofol [40]. In this method, propofol is oxidised in the presence of hydrogen peroxide in a reaction catalysed by the enzyme

Fig. 1 Gibbs reaction for propofol. Propofol reacts with DCQ to produce a coloured indophenol. Adapted from Mistry et al. [35]

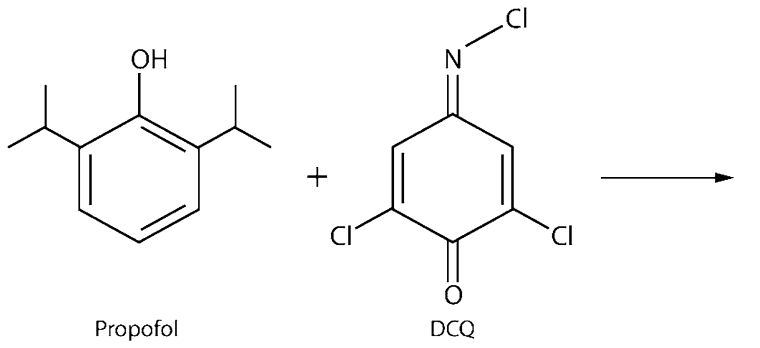<smiles>CC(C)c1cc(N=C2C=C(Cl)C(=O)C(Cl)=C2)cc(C(C)C)c1O</smiles> 
horseradish peroxidase (HRP). The product of this reaction is then coupled with 4-aminoantipyrine, producing a coloured solution, the absorbance of which is measured at $485 \mathrm{~nm}$. By this method the authors report a propofol detection limit of $1.6 \mu \mathrm{g} / \mathrm{ml}$ with a linear range of 5 to $100 \mu \mathrm{g} / \mathrm{ml}$. However, this approach was developed for the determination of propofol concentrations within commercial propofol emulsions, rather than within biological fluids. This same group compared the above method with a fluorometric method. By measuring the fluorescent emission of propofol at $347 \mathrm{~nm}$ in ethanol, they were able to detect propofol with a limit of detection of $1.3 \mu \mathrm{g} / \mathrm{ml}$ and a linear range of 4 to $243 \mu \mathrm{g} / \mathrm{ml}$.

$\mathrm{Li}$ et al. have also utilised fluorescence spectroscopy for propofol detection [41]. Using an optical fibre with an online MIP for solid phase extraction, they have demonstrated propofol detection in whole blood with two distinct linear ranges between 0.1 and $15 \mu \mathrm{g} / \mathrm{ml}$. These two linear regions are the result of two different types of binding site within the MIP. The authors report a time-to-results of $5 \mathrm{~min}$.

This same group has also used a similar optical fibre to detect propofol via spectrophotometry. By reacting propofol with a diazonium salt, a coloured product can be formed with an absorption peak at $483 \mathrm{~nm}$. In this manner the authors have demonstrated the detection of propofol in plasma samples across a linear range of 3 to $18 \mu \mathrm{g} / \mathrm{ml}$ [42]. Additionally, this group has developed a technique exploiting graphene quantum dots for the detection of propofol via fluorescence photometry. In the presence of the enzyme HRP and hydrogen peroxide, propofol will be oxidised to form 2,6-diisopropylquinone. This quinone will quench the natural fluorescence of the quantum dots, allowing for the detection of propofol to a limit of $0.5 \mu \mathrm{g} / \mathrm{ml}$ with a linear range of 5.34 to $89.07 \mu \mathrm{g} / \mathrm{ml}$. This method was developed for the detection of propofol in emulsions [43].

El Sharkasy et al. have developed a method for the simultaneous detection of propofol and cisatracurium (a muscle relaxant commonly co-administered with propofol) by derivative synchronous spectrofluorometry [44]. By analysing the first derivative spectra at $279.6 \mathrm{~nm}$, this group were able to demonstrate the detection of propofol in spiked serum samples across a linear range of 40 to $400 \mathrm{ng} / \mathrm{ml}$ with a detection limit of $4 \mathrm{ng} / \mathrm{ml}$. No indication is given as to the reporting time of this technique, although when detecting propofol in human serum the authors employed a protein precipitation technique that requires tens of minutes to perform. A summary of reported optical propofol detection techniques is presented in Table 3.

\subsection{Electrochemical techniques}

It is possible to detect propofol by electrochemical techniques [24, 25, 45]. However, it is well documented that the electrochemical oxidisation of propofol will result in the deposition of an insoluble polymer film on the electrode resulting in the rapid passivation (or fouling) of the electrode surface [46-51]. The group of Lindner et al. have shown that propofol can be detected using stripping voltammetry, but that the electrode needs to be replaced or freshly polished after each measurement [45]. The same group have also reported that propofol can be detected without electrode fouling by using a restricted potential window. However, this approach results in a problematic lack of specificity. In order to address these issues, this group have developed a technique whereby electrodes are coated with a plasticised polyvinyl chloride (PVC) membrane which prevents electrode fouling, improves selectivity and lowers the limit of detection [2, 52, 53]. Propofol is highly lipophilic, and therefore it will be present in the organic membrane at a far higher concentration than an aqueous medium. Commonly interfering compounds are more hydrophilic, and will hence be less preferentially absorbed into the film. Using this technique, this group have demonstrated chronoamperometric detection of
Table 3 Summary of reported optical propofol detection and quantification techniques

\begin{tabular}{llll}
\hline Technique & $\operatorname{LoQ}^{\mathrm{a}}(\mu \mathrm{g} / \mathrm{ml})$ & Range $(\mu \mathrm{g} / \mathrm{ml})$ & References \\
\hline Spectrophotometry (Gibbs) & 0.84 & $1-5$ & {$[36]$} \\
Spectrophotometry (Gibbs/MIP) & 0.75 & $0.25-10$ & {$[37]$} \\
Spectrophotometry (Gibbs) & 0.75 & $0.75-12$ & {$[38]$} \\
Spectrophotometry (HRP) & 5.3 & $5-100$ & {$[40]$} \\
Spectrophotometry (diazonium salt) & 2.14 & $3-18$ & {$[42]$} \\
Fluorometry & 4.3 & $4-243$ & {$[40]$} \\
Fluorometry (MIP) & $\mathrm{NR}$ & $0.1-15$ & {$[41]$} \\
Fluorometry (quantum dots) & 1.5 & $5.34-89.07$ & {$[43]$} \\
Derivative synchronous spectrofluorometry & 0.0121 & $0.04-0.4$ & {$[44]$} \\
\hline
\end{tabular}

$N R$ not reported

${ }^{a}$ Where a limit of detection (LoD) is stated in preference to a limit of quantification (LoQ), LoQ is assumed to be three times LoD 
propofol using both glassy carbon and gold electrodes. They have reported a limit of detection of approximately $14 \mathrm{ng} / \mathrm{ml}$, a linear range up to approximately $3.5 \mu \mathrm{g} / \mathrm{ml}$ and have demonstrated the detection of propofol in spiked human serum. One issue regarding PVC membranes is whether they possess physical and mechanical properties suitable for long-term, continuous usage [54]. This group have demonstrated these sensors for up to three hours of continuous use.

Hong et al. have addressed the selectivity issues by the application of a MIP [55] (this same group's application of MIPs to optical propofol detection was outlined in the preceding section). They have developed a propofol specific MIP based on the conductive polymer polypyrrole, which is electropolymerised upon gold interdigitated electrodes. The binding of propofol to this MIP results in changes to the surface electrical properties, leading to a drop in the conductivity (Fig. 2). In this manner, this group has demonstrated a disposable biochip for chemiresistive propofol detection. The authors report a limit of detection of $0.1 \mu \mathrm{g} / \mathrm{ml}$ with a linear range of 0.1 to $30 \mu \mathrm{g} / \mathrm{ml}$ and a time-to-results of $25 \mathrm{~s}$. However, continuous measurement has not yet been demonstrated. Additionally, with MIP sensors there is a possibility of slow mass transfer of the analyte to the active sites, if the pore-size distribution is heterogeneous, which is undesirable for long-term, continuous propofol monitoring [56].
Stradolini et al. have demonstrated a technique where the fouling of the electrode during propofol detection is mitigated by the inclusion of periodic electrode cleaning steps [15]. Using either boron doped diamond or pencil graphite electrodes, this group were able to demonstrate the continuous voltammetric monitoring of propofol in serum over $4 \mathrm{~h}$ by intermittently performing either a cyclic voltammetry-based cleaning procedure in sodium hydroxide or a chronoamperometry-based cleaning procedure in phosphate buffered saline. However, it is unclear how practical these cleaning steps would prove in the context of realworld propofol monitoring during general anaesthesia. This group reports a limit of detection of approximately $0.42 \mu \mathrm{g} /$ $\mathrm{ml}$ using cyclic voltammetry. A summary of reported electrochemical propofol detection techniques is presented in Table 4.

\section{Challenges and future prospects}

The aim of delivering real-time monitoring of blood propofol concentration during general anaesthesia places a number of requirements on any potential propofol sensing technique. For instance, any method must be capable of returning results within a sufficiently narrow window of time to provide information that is of practical use to anaesthetists or

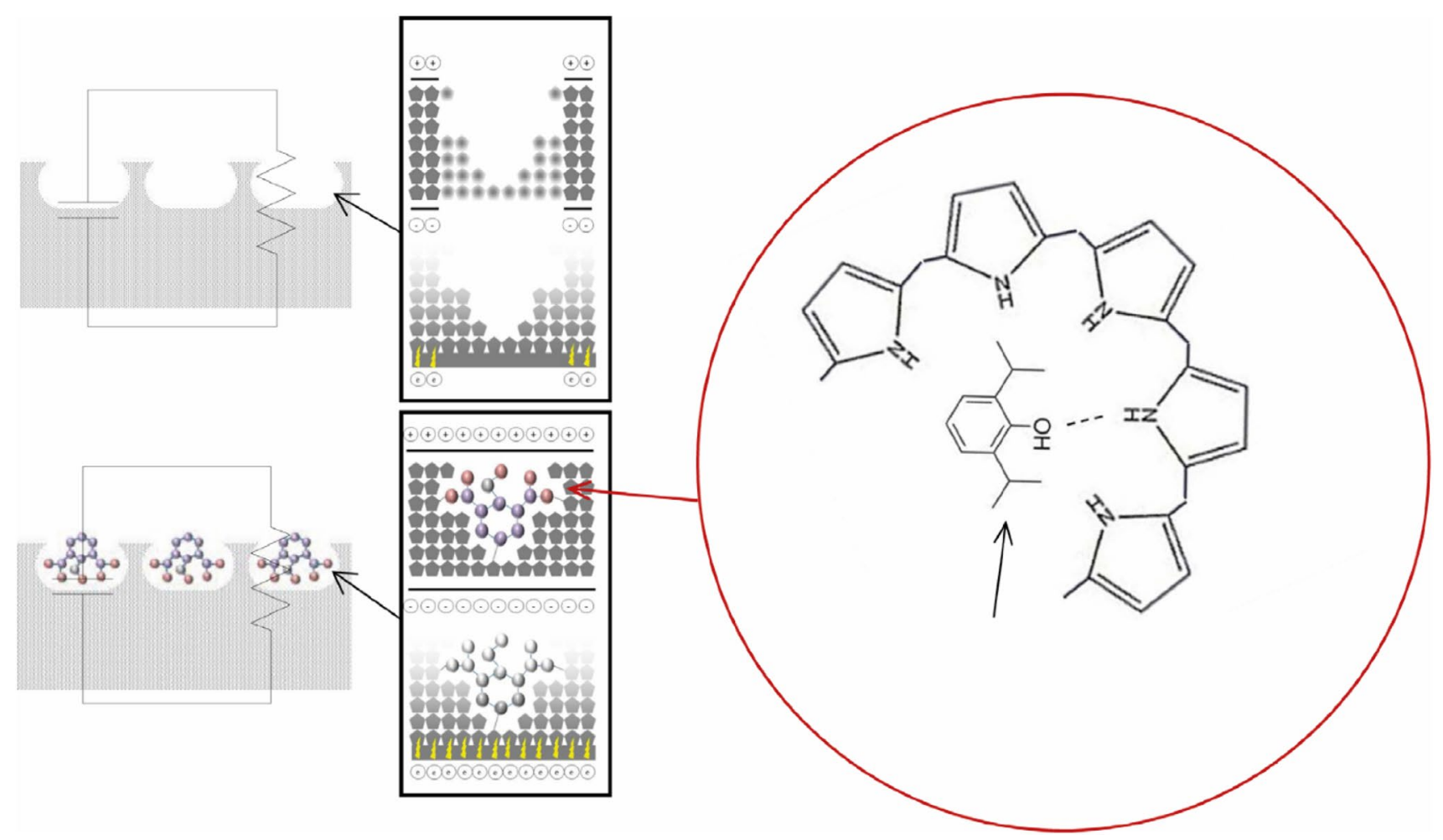

Fig. 2 Representation of the binding of propofol molecules to a conductive molecularly imprinted polymer (MIP) and the associated equivalent circuit diagram. Reprinted with permission [55] Copyright Elsevier 2016 
Table 4 Summary of reported electrochemical propofol detection and quantification techniques

\begin{tabular}{llll}
\hline Technique & LoQ $^{\mathrm{a}}(\mu \mathrm{g} / \mathrm{ml})$ & Range $(\mu \mathrm{g} / \mathrm{ml})$ & References \\
\hline $\begin{array}{l}\text { Amperometry/PVC } \\
\text { membrane }\end{array}$ & $0.043^{\mathrm{b}}$ & $0-3.5^{\mathrm{b}}$ & {$[2]$} \\
$\begin{array}{l}\text { Chemiresistive MIP } \\
\begin{array}{c}\text { Voltammetry with inter- } \\
\text { mittent cleaning steps }\end{array}\end{array}$ & 0.3 & $0.1-30$ & {$[55]$} \\
\hline
\end{tabular}

$N R$ not reported

${ }^{a}$ Where a limit of detection (LoD) is stated in preference to a limit of quantification (LoQ), LoQ is assumed to be three times LoD

${ }^{\mathrm{b}}$ Converted from $\mu \mathrm{M}$

other healthcare professionals. This is a major reason why approaches such as HPLC and mass spectrometry, which have a time-to-results of the order of several tens of minutes at best [28], are of limited utility for this application. Methods that require non-trivial sample pre-treatment will likely not be suitable for this same reason, and as such, sensors capable of functioning at physiological conditions will likely be more suitable than those that are not (for instance optical techniques based on the Gibbs reaction, which requires alkaline conditions [36-38]).

There are examples of groups who have reported the detection of propofol in urine as well as blood [28, 36]. However, due to the significant time-lag between administering a drug and it or its metabolites presenting in a patient's urine, this approach will not be applicable to real-time propofol monitoring during general anaesthesia. Whole blood, serum or plasma represent the most practical biological fluids for this application.

To be of use for patient monitoring in a surgical context, any sensor system would need to be capable of producing stable results over the duration of a surgical procedure, potentially $8 \mathrm{~h}$ or longer. Furthermore, it has been shown that propofol will slowly redistribute between the plasma and blood cell membranes over time [57], meaning that the time between the collection and measurement of a sample will need to be tightly controlled. As such, any technique for real-time propofol monitoring must be suitable for automation, with minimal sample processing.

It is likely during general anaesthesia that propofol will be co-administered with other drugs, and as such it is necessary that any propofol sensor possess a sufficient degree of specificity. The Gibbs reagent will react with any phenolic molecule, so any optical detection technique based on the Gibbs reaction may face specificity issues if any co-administered drugs contain phenol groups. Approaches based on similar colourimetric techniques will face similar issues. Likewise, any fluorometric approach will need to ensure that there are no interfering compounds with overlapping excitation or emission windows. Specificity will also be a particular challenge for electrochemical approaches as the potential window in which propofol is electrochemically oxidised corresponds to the electroactive window for many potential interfering compounds [53].

One potential approach to improving the specificity of propofol sensors is the use of MIPs [37, 42, 55]. However, MIPs possess a finite number of binding sites and therefore may suffer from saturation effects over long timescales. Additionally, as discussed previously, there is the potential for slow mass transfer [56]. Another potential approach for improving the specificity of propofol sensors are membrane coated electrodes such as those developed by Linder et al. [2, $52,53]$. However, the performance of such electrodes over time periods of several hours has yet to be fully investigated.

When demonstrating propofol detection in plasma, serum or whole blood, the groups discussed in Sects. 2.2 and 2.3 mostly make use of spiked samples rather than real samples from patients or animals who have been administered propofol. It is known that approximately $98 \%$ of the blood concentration of propofol is bound, either to erythrocytes or serum proteins, with only the remaining $2 \%$ existing free in solution [58]; the latter free-fraction most likely being the pharmacologically active drug. Therefore, it is unclear how representative spiked samples will prove, particularly in cases such as MIPs or membrane coated electrodes where protein binding may hinder the transport of the propofol molecules to the sensor surface. Any real-time propofol detection technique intended for use with whole blood, serum or plasma will either need to be capable of detecting both bound and unbound propofol or to be capable of detecting propofol in concentration ranges up to two orders of magnitude lower than the therapeutic range (typically $0.25-10 \mu \mathrm{g} / \mathrm{ml}$ [52]). Few of the emerging technologies discussed in this review have sensitivities even approaching this range.

Future work in this field is likely to be focussed upon achieving the required sensitivities for the detection of the free-fraction of propofol in blood and demonstrating the required specificity to reliably differentiate propofol from potential interfering compounds. This work will be coupled with efforts to integrate such sensors with automated sample collection and processing technologies in order to achieve the real-time monitoring of blood propofol concentration that is required for the monitoring of patients undergoing general anaesthesia.

\section{Concluding remarks}

Despite increasing evidence of the many advantages of TIVA compared to conventional volatile-based anaesthesia, both in terms of patient outcomes and environmental impact, TIVA still only accounts for a small percentage of administered general anaesthetics worldwide. The principle 
obstacle to a more widespread use of TIVA is the lack of suitable methods for monitoring a patient's blood propofol concentration in real time. Existing methods such as HPLC and mass spectroscopy are too complex, expensive and slow to return results. In recent years there has been much progress in emerging propofol sensing techniques, consisting of both optical and electrochemical approaches. However, many challenges still remain, particularly in terms of sensitivity and sensor lifetime.

Electrochemical approaches are attractive due to their potential for high sensitivity and ease of automation, but possess significant challenges in terms of specificity and the potential for electrode fouling. In contrast, optical techniques generally require a greater degree of sample preparation and have not yet been demonstrated to be as suitable for continuous measurement.

Future work in this area will likely focus on improvements to sensitivity and specificity and on integrating sensors into technologies to enable automated and continuous measurement.

Acknowledgements This paper was produced as part of an Innovate UK Biomedical Catalyst Award. The authors would like to thank Dr Mark O'Connell, Dr Tim Craft and Prof John Sear, all of Somnus Scientific Limited, for their comments and suggestions.

Funding This paper was produced as part of an Innovate UK Biomedical Catalyst Award.

\section{Declarations}

Conflict of interest The authors have no known competing interests that could have appeared to influence the work reported in this paper.

Ethics approval Not applicable.

Consent to participate Not applicable.

Consent for publication Not applicable.

Open Access This article is licensed under a Creative Commons Attribution 4.0 International License, which permits use, sharing, adaptation, distribution and reproduction in any medium or format, as long as you give appropriate credit to the original author(s) and the source, provide a link to the Creative Commons licence, and indicate if changes were made. The images or other third party material in this article are included in the article's Creative Commons licence, unless indicated otherwise in a credit line to the material. If material is not included in the article's Creative Commons licence and your intended use is not permitted by statutory regulation or exceeds the permitted use, you will need to obtain permission directly from the copyright holder. To view a copy of this licence, visit http://creativecommons.org/licenses/by/4.0/.

\section{References}

1. Sahinovic MM, Struys MMRF, Absalom AR. Clinical pharmacokinetics and pharmacodynamics of propofol. Clin
Pharmacokinet. 2018;57:1539-58. https://doi.org/10.1007/ s40262-018-0672-3.

2. Kivlehan F, Chaum E, Lindner E. Propofol detection and quantification in human blood: the promise of feedback controlled, closed-loop anesthesia. Analyst. 2015;140:98-106. https://doi.org/ 10.1039/C4AN01483A.

3. Laurila T, Sorajarvi T, Saarela J, Toivonen J, Wheeler DW, Ciaffoni L, Ritchie GAD, Kaminski CF. Optical detection of the anesthetic agent propofol in the gas phase. Anal Chem. 2011;83:39637. https://doi.org/10.1021/ac200690f.

4. Lewis MC, Nevo I, Paniagua MA, Ben-Ari A, Pretto E, Eisdorfer $\mathrm{S}$, Davidson E, Matot IEC. Uncomplicated general anesthesia in the elderly results in cognitive decline: does cognitive decline predict morbidity and mortality? Med Hypotheses. 2007;68:484-92. https://doi.org/10.1016/j.mehy.2006.08.030.

5. Mellon RD, Simone AF, Rappaport BA. Use of anesthetic agents in neonates and young children. Pediatr Anesth. 2007;104:50920. https://doi.org/10.1213/01.ane.0000255729.96438.b0.

6. Xie Z, Dong Y, Maeda U, Moir RD, Xia W, Culley DJ, Crosby G, Tanzi RE. The inhalation anesthetic isoflurane induces a vicious cycle of apoptosis and amyloid beta-protein accumulation. J Neurosci. 2007;27:1247-54. https://doi.org/10.1523/JNEUROSCI. 5320-06.2007.

7. Wigmore TJ, Mohammed K, Jhanji S. Long-term survival for patients undergoing volatile versus IV anesthesia for cancer surgery. Anesthesiology. 2016;124:69-79. https://doi.org/10.1097/ ALN.0000000000000936.

8. Wall T, Sherwin A, Ma D, Buggy DJ. Influence of perioperative anaesthetic and analgesic interventions on oncological outcomes: a narrative review. Br J Anaesth. 2019;123:135-50. https://doi. org/10.1016/j.bja.2019.04.062.

9. Ryan SM, Nuelsen CJ. Global warming potential of inhaled anesthetics: application to clinical use. Anesth Analg. 2010;111:92-8. https://doi.org/10.1213/ANE.0b013e3181e058d7.

10. Campbell M, Pierce JMT. Atmospheric science, anaesthesia, and the environment. BJA Educ. 2015;15:173-9. https://doi.org/10. 1093/bjaceaccp/mku033.

11. Vollmer MK, Rhee TS, Rigby M, Hostetter D, Hill M, Schoenenberger F, Reimann S. Modern inhalation anesthetics: potent greenhouse gases in the global atmosphere. Geophys Res Lett. 2015;42:1606-11. https://doi.org/10.1002/2014GL062785.

12. Hornuss C, Praun S, Villinger J, Dornauer A, Moehnle P, Weniger DME, Chouker A, Feil C, Briegel J, Thiel M, Schelling G. Real-time monitoring of propofol in expired air in humans undergoing total intravenous anesthesia. J Am Soc Anesthesiol. 2007;106:665-74. https://doi.org/10.1097/01.anes.0000264746. 01393.e0.

13. Perl T, Carstens E, Hirn A, Quintel M, Vautz M, Nolte J, Junger M. Determination of serum propofol concentrations by breath analysis using ion mobility spectrometry. Br J Anaesth. 2009;103:822-7. https://doi.org/10.1093/bja/aep312.

14. Zhang F, Dong H, Zhang X, Guo J, Liu Y, Zhou C, Zhang X, Liu J, Yan M, Chen X. A non-invasive monitoring of propofol concentration in blood by a virtual surface acoustic wave sensor array. Anal Sci. 2017;33:1271-7. https://doi.org/10.2116/analsci. 331271.

15. Stradolini F, Kilic T, Taurino I, De Micheli G, Carrara S. Cleaning strategy for carbon-based electrodes: long-term propofol monitoring in human serum. Sens Actuators, B. 2018;269:304-13. https:// doi.org/10.1016/j.snb.2018.04.082.

16. Yeganeh MH, Ramzan I. Determination of propofol in rat whole blood and plasma by high performance liquid chromatography. $\mathrm{J}$ Chromatogr B. 1997;691:478-82. https://doi.org/10.1016/S03784347(96)00469-0.

17. Knibbe CAJ, Koster VS, Deneer VHM, Stuurman RM, Kuks PFM, Lange R. Determination of propofol in low-volume samples 
by high performance liquid chromatography with fluorescence detection. J Chromatogr B. 1998;706:305-10. https://doi.org/10. 1016/S0378-4347(97)00571-9.

18. Cussonneau X, De Smet E, Lantsoght K, Salvi J-P. A rapid and simple HPLC method for the analysis of propofol in biological fluids. J Pharm Biomed Anal. 2007;44:680-2. https://doi.org/10. 1016/j.jpba.2006.10.020.

19. Nishio T, Suzuki R, Tsukada Y, Kanazawa H, Okano T, MiyabeNishiwaki T. Aqueous chromatographic system for the quantification of propofol in biological fluids using a temperatureresponsive polymer modified stationary phase. J Chromatogr A. 2009;1216:7427-32. https://doi.org/10.1016/j.chroma.2009.04. 047.

20. Ayad MM, Belal F, Hosney MM, Elmansi H, Elsayed N. Simultaneous HPLC determination of cisatracurium and propofol in human plasma via fluorometric detection. J Chromatogr Sci. 2018;56:524-30. https://doi.org/10.1093/chromsci/bmy027.

21. Vishwanathan K, Stewart JT. HPLC determination of a propofol and remifentanil mixture. J Liq Chromatogr Relat Technol. 1999;22:923-31. https://doi.org/10.1081/JLC-100101708.

22. Zhang H, Wang P, Bartlett MG, Stewart JT. HPLC determination of cisatracurium besylate and propofol mixtures with LC-MS identification of degradation products. J Pharm Biomed Anal. 1998;16:1241-9. https://doi.org/10.1016/S0731-7085(97) 00262-8

23. Teshima D, Nagahama H, Makino K, Kataoka Y, Oishi R. Microanalysis of propofol in human serum by semi-microcolumn highperformance liquid chromatography with UV detection and solidphase extraction. J Clin Pharm Ther. 2001;26:381-5. https://doi. org/10.1046/j.1365-2710.2001.00375.x.

24. Dowrie RH, Ebling WF, Mandema JW, Stanski DR. High-performance liquid chromatographic assay of propofol in human and rat plasma and fourteen rat tissues using electrochemical detection. J Chromatogr B. 1996;678:279-88. https://doi.org/10.1016/03784347(95)00475-0.

25. Pissinis DE, Marioli JM. Elecrochemical detection of 2,6-diisopropylphenol (propofol) in reversed phase HPLC at high $\mathrm{pH}$. J Liq Chromatogr Relat Technol. 2007;30:1787-95. https://doi.org/10. 1080/10826070701360475.

26. Guitton J, Desage M, Lepape A, Degoute CS, Manchon M, Brazier JL. Quantification of propofol in whole blood by gas chromatography-mass spectrometry. J Chromatogr B. 1995;669:358-65. https://doi.org/10.1016/0378-4347(95)00105-R.

27. Hikiji W, Kudo K, Usumoto Y, Tsuji A, Ikeda N. A Simple and sensitive method for the determination of propofol in human solid tissues by gas chromatograhy-mass spectrometry. J Anal Toxicol. 2010;34:389-93. https://doi.org/10.1093/jat/34.7.389.

28. Lee SY, Park N-H, Jeong E-K, Wi J-W, Kim C-J, Kim JY, In MK, Hong J. Comparison of GC/MS and LC/MS methods for the analysis of propofol and its metabolites in urine. J Chromatogr B. 2012;900:1-10. https://doi.org/10.1016/j.jchromb.2012.05.011.

29. Bajpai L, Varshney M, Seubert CN, Dennis DM. A new method for the quantitation of propofol in human plasma: efficient solid-phase extraction and liquid chromatography/APCI-triple quadrupole mass spectrometry detection. J Chromatogr B. 2004;810:291-6. https://doi.org/10.1016/j.jchromb.2004.08.023.

30. Beaudry F, Guenette SA, Andrew Winterborn A, Marier J-F, Vachon P. Development of a rapid and sensitive LC-ESI/MS/MS assay for the quantification of propofol using a simple off-line dansyl chloride derivatization reaction to enchance signal intensity. J Pharm Biomed Anal. 2005;39:411-7. https://doi.org/10.1016/j. jpba.2005.04.041.

31. Cohen S, Lhuiller F, Mouloua Y, Vignal B, Favetta P, Guitton J. Quantitative measurement of propofol and in main glucuroconjugate metabolites in human plasma using solid phase extractionliquid chromatography-tandem mass spectrometry. J Chromatogr
B. 2007;854:165-72. https://doi.org/10.1016/j.jchromb.2007.04. 021.

32. Sorensen LK, Hasselstrom JB. Simultaneous determination of propofol and its glucuronide in whole blood by liquid chromatography-electrospray tandem mass spectrometry and the influence of sample storage conditions on the reliability of the test results. J Pharm Biomed Anal. 2015;109:158-63. https://doi.org/10.1016/j. jpba.2015.02.035.

33. Vaiano F, Serpelloni G, Focardi M, Fioravanti A, Mari F, Bertol E. LC-MS/MS and GC-MS methods in propofol detection: evaluation of the two analytical procedures. Forensic Sci Int. 2015;256:1-6. https://doi.org/10.1016/j.forsciint.2015.07.013.

34. Arip MNM, Heng LY, Ahmad M, Hasbullah SA. Reaction of 2,6-dicholroquinone-4-chloroimide (Gibbs reagent) with permethrin - an optical sensor for rapid detection of permethrin in treated wood. Chem Cent J. 2013;7:122. https://doi.org/10.1186/ 1752-153X-7-122.

35. Mistry S, Wenthold PG. Mass spectrometric detection of the Gibbs reaction for phenol analysis. J Mass Spectrom. 2018;53:947-53. https://doi.org/10.1002/jms.4261.

36. Gad-Kariem EA, Abounassif MA. Colorimetric determination of propofol in bulk form, dosage form and biological fluids. Anal Lett. 2000;33:2515-31. https://doi.org/10.1080/0003271000 8543206.

37. Hong C-C, Chang P-H, Lin C-C, Hong C-L. A disposable microfluidic biochip with on-chip molecularly imprinted biosensors for optical detection of anesthetic propofol. Biosens Bioelectron. 2010;25:2058-64. https://doi.org/10.1016/j.bios.2010.01.037.

38. Liu B, Pettigrew DM, Bates S, Laitenberger PG, Troughton G. Performance evaluation of a whole blood propofol analyser. J Clin Monit Comput. 2012;26:29-36. https://doi.org/10.1007/ s10877-011-9330-0.

39. De Vries A, Taylor PM, Troughton G, Liu B, Fowden AL, Swear JW. Real time monitoring of propofol blood concentration in ponies anaesthetized with propofol and ketamine. J Vet Pharmacol Ther. 2012;36:258-66. https://doi.org/10.1111/j.1365-2885.2012. 01422.x.

40. Sramkova I, Amorim CG, Sklenarova H, Montenegro MCBM, Horstkotte B, Araujo AN, Solich P. Fully automated analytical procedure for propofol determination by sequential injection technique with spectrophotometric and fluorimetric detections. Talanta. 2014;118:104-10. https://doi.org/10.1016/j.talanta.2013. 09.059 .

41. Li L, Ding H, Di B, Li W, Chen J. Rapid detection of propofol in whole blood using an automated on-line molecularly imprinted pretreatment coupled with optical fibre detection. Analyst. 2012;137:5632-8. https://doi.org/10.1039/C2AN35523J.

42. Li L, Li Y. Study of azo-coupling derivatization by sequential injection coupled with spectrophotometric optical fibre detection for propfol analysis. Anal Methods. 2016;8:6176-84. https://doi. org/10.1039/C6AY01047D.

43. Diao J, Wang T, Li L. Graphene quantum dots as nanoprobes for fluorescent detection of propofol in emulsions. R Soc Open Sci. 2019;6:181753. https://doi.org/10.1098/rsos.181753.

44. El Sharkasy ME, Walask M, Belal F, Salim MM. First derivative synchronous spectrofluorimetric method for the simultaneous determination of propofol and cisatracurium besylate in biological fluids. Luminescence. 2020;35:312-20. https://doi.org/10.1002/ bio. 3729 .

45. Langmaier J, Garay F, Kivlehan F, Chaum E, Lindner E. Electrochemical quantification of 2,6-diisopropylphenol (propofol). Anal Chim Acta. 2011;704:63-7. https://doi.org/10.1016/j.aca.2011.08. 003.

46. Andreescu S, Andreescu D, Sadik OA. A new electrocatalytic mechanism for the oxidation of phenols at platinum electrodes. 
Electrochem Commun. 2003;5:681-8. https://doi.org/10.1016/ S1388-2481(03)00166-8.

47. Ferreira M, Varela H, Torresi RM, Tremiliosi-Filho G. Electrode passivation caused by polymerization of different phenolic compounds. Electrochim Acta. 2006;52:434-42. https://doi.org/10. 1016/j.electacta.2006.05.025.

48. Dejmkova H, Scampicchio M, Zima J, Barek J, Mannino S. Determination of total phenols in food by boron doped diamond electrode. Electroanalytical. 2009;21:1014-8. https://doi.org/10.1002/ elan.200804508.

49. Teofilo RF, Kiralj R, Ceragiolo HJ, Peterlevitz AC, Baranauskas V, Kubota LT, Ferreira MC. QSPR study of passivation by phenolic compounds at platinum and boron-doped diamond electrodes. J Electrochem Soc. 2008;155:D640-50. https://doi.org/10. 1149/1.2953588.

50. Bao L, Xiong R, Wei. Electrochemical polymerization of phenol on 304 stainless steel anodes and subsequent coating structure analysis. Electrochim Acta. 2010;55:4030-8. https://doi.org/10. 1016/j.electacta.2010.02.052.

51. Yang X, Kirsch J, Simonian A. Modeling analysis of electrode fouling during electrolysis of phenolic compounds. Electrochim Acta. 2013;94:259-68. https://doi.org/10.1016/j.electacta.2013. 01.019 .

52. Kivlehan F, Garay F, Guo J, Chaum E, Lindner E. Toward feedback-controlled anesthesia: voltammetric measurement of propofol (2,6-diisopropylphenol) in serum-like electrolyte solutions. Anal Chem. 2012;84:7670-6. https://doi.org/10.1021/ac3006878.

53. Rainey F, Kivlehan F, Chaum E, Lindner E. Toward feedback controled anesthesia: automated flow analytical system for electrochemical monitoring of propofol in serum solutions. Electroanalytical. 2014;26:1295-303. https://doi.org/10.1002/elan. 201300585.

54. Ganjali MR, Larijani B, Norouzi P. Determination of midazolam by potentiometric PVC membrane and MWCNTs based carbon paste sensors. Int J Electrochem Sci. 2012;7:4822-33.

55. Hong C-C, Lin C-C, Hong C-L, Lin Z-X, Chung M-H, Hsieh P-W. Handheld analyzer with on-chip molecularly-imprinted biosensors for electrochemical detection of propofol in plasma samples. Biosens Bioelectron. 2016;86:623-9. https://doi.org/10.1016/j.bios. 2016.07.032.

56. Haupt K. Molecularly imprinted polymers: the next generation. Anal Chem. 2003;75:377A-83A. https://doi.org/10.1021/ac031 385h.

57. Fan S-Z, Yu H-Y, Chen Y-L, Liu C-C. Propofol concentration monitoring in plasma or whole blood by gas chromatography and high-performance liquid chromatography. Anesth Analg. 1995;81:175-8.

58. Mazoit JX, Samii K. Binding of propofol to blood components: implications for pharmacokinetics and for pharmacodynamics. $\mathrm{Br}$ J Clin Pharmacol. 1999;47:35-42. https://doi.org/10.1046/j.13652125.1999.00860.x.

Publisher's Note Springer Nature remains neutral with regard to jurisdictional claims in published maps and institutional affiliations. 